\title{
Günlük Döviz Kurları ile İstanbul Şehir Endeksi Arasında Getiri ve Volatilite Yayılımı
}

\author{
Sevilay SEZGiN ${ }^{1 *}$ \\ ${ }^{1}$ Scientist, Turkey
}

Geliş Tarihi/Received: 29.03.2020

Kabul Tarihi/Accepted: 11.06.2020

Araştırma Makalesi/Research Article

\section{ÖZET}

Şehir endeksleri hesaplandığı bölgedeki işletmelerin finansal durumu hakkında bilgi vermektedir. Ayrıca belirsizliğin olduğu bir durumda yatırım yapmak isteyen yatırımcılara yol gösterici niteliktedir. Türkiye'deki şehir endeksleri ise Borsa İstanbul (BİST) pay endeksleri bünyesinde hesaplanmaktadır. Diğer bir yandan borsa yatırımcılarının yatırım kararları üzerinde birçok dış faktör etkili olmaktadır. Döviz kurlarındaki değişimler ise bu etkenlerin en önemlileri arasındadır. Buna bağlı olarak bu etkileşim bu çalışmanın da ortaya çıkmasına ilham kaynağı olmuştur.

Bu çalışmada, BİST Şehir Endeksleri içerisinde hesaplanan İstanbul şehir endeksi ile günlük döviz kuru verisi arasındaki getiri ve volatilite yayılımı araştırılmıştır. 02.01.2014-26.02.2020 tarihleri arasında gün sonu verileri kullanılarak çok değişkenli VAR-EGARCH modeli çalıştırılmıştır. Çalışmadan elde edilen ampirik bulgulara göre İstanbul şehir endeksi hariç diğer değişkenler üzerinde negatif şokların pozitif şoklardan daha baskın olduğu görülmüştür. Ayrıca modeldeki varyans denklemi sonuçlarına göre döviz kurlarının İstanbul şehir endeksi üzerine volatilite yayılımı gerçekleştirdiği sonucuna ulaşılmıştır.

Anahtar kelimeler: Volatilite, Döviz Kuru, Şehir Endeksleri, VAR-EGARCH. 


\title{
Sezgin, $S$.
}

\section{Return and Volatility Spillover Between Daily Exchange Rates and Istanbul City Index}

\begin{abstract}
City indices provide information about the financial stuations of businesses in the region where they were calculated. It is also a guide for investors who want to invest in a situation of uncertainty. The city indices in Turkey, has calculated under the İstanbul Stock Exchange (BIST) share indices. On the other hand, many external factors affect the investment decisions of stock market investors. The changes in exchange rates is among the most important of these factors. Accordingly, this interaction was inspired the emergence of this study.

In this study, the return and volatility spillover between the Istanbul city index calculated in the BIST City Indices and the daily exchange rate data were investigated. The multivariate VAREGARCH model was run between the dates of 02.01.2014-26.02.2020 using the end of daily data. According to the empirical findings obtained from the study, it was observed that negative shocks were more dominant than positive shocks on other variables except for the Istanbul city index. In addition, according to the results of the variance equation in the model, it was concluded that the exchange rates spread volatility on the Istanbul city index.
\end{abstract}

Keywords: Volatility, Exchange Rate, City Indices.

\section{GíRiş}

Finansal piyasalarda bulunan varlıkların fiyatlarında oluşan ani hareketler (oynaklık), uluslararası finans literatürünün en önemli tartışma konularından birisidir. Öngörülemeyen (iç ve dış politik durumlar, iç ve dış ticarette meydana gelen gelişmeler, faiz oranları, şirketlerin durumlarından kaynaklanan işlem düzeylerindeki hareketler, rekabet) beklenmedik iniş veya çıkışlar (dalgalanmalar) şeklinde tanımı yapılan oynaklık, yapılacak yatırımların karlılığı hususunda belirsizlik yarattığı için yatırımcıların portföy çeşitlendirmek için aldıkları kararlar üzerinde etkili olabilmektedir (Ergün, 2010: 1).

Yatırımcıların yatırım kararları almalarında önemli bir etkisi olan BİST, bünyesinde çeşitli endeksleri bulundurmaktadır. Bunlardan biri olan BİST 100 pay endeksleridir. BİST 100 pay endeksleri kapsamında, 2009 yılından itibaren hesaplanmaya başlanan BİST Şehir Endeksleri bulunduğu bölgede en az 5 işletme ile BİST Şehir Endeksleri'nde işlem görmeye başlayan işletmeleri göstermektedir. 
Ayrıca BİST İstanbul şehir endeksi 31.12.2008 tarihinden itibaren borsada işlem görmeye başlamıştır. Borsadaki başlangıç değeri 28.864,07'dir. Güncel veriler 1şı̆̆ında bünyesinde 101 şirket yer almaktadır. Şirketler faaliyet gösterdikleri sektörlere göre kendi içinde kollara ayrılmaktadır. Bu sektörler ve sektörlerde faaliyet gösteren şirketler sınıflandırılırsa; İmalat Sanayi: 28, İdari ve Destek Hizmet Faaliyetleri: 4, İnşaat ve Bayındırlık: 8, Elektrik, Gaz ve Su: 3, Mali Kuruluşlar: 28, Toptan ve Perakende: 6, Teknoloji: 13, Eğitim, Sağlık, Spor ve Diğer Hizmetler: 4, Ulaştırma, Haberleşme ve Depolama: 6, Mesleki, Bilimsel ve Teknik Faaliyetler: 1 olmak üzere bir dağılım söz konusu olmaktadır (KAP, Erişim Tarihi: 27.03.2020).

Çalışma dört ana bölümden oluşmakta olup öncelikle giriş kısmında konunun önemine ve çalışmanın yapıldığı tarih itibari ile İstanbul şehir endeksinde işlem gören şirketlerin genel durumu hakkında güncel bilgiler paylaşılmıştır. İkinci bölümde ise literatürdeki konuyla ilgili yapılan çalışmalardan bahsedilmiştir. Üçüncü bölümde çalışmanın amacı, yöntemi ve kullanılan veri setinden bahsedilmiştir. Dördüncü bölümünde analizden elde edilen bulgular ve yorumları eklenerek çalışmanın literatüre yaptığı katkılar belirtilecektir. Son olarak da analiz sonuçları yapılan literatür çalışmaları ile ilişkilendirilip bu alanda yapılan başka çalışmalara, politika yapıcılara ve yatırımcıya tavsiyeler niteliğinde derlenip sonuçlandırılacaktır.

\section{LITERATÜR ÇALIŞMASI}

Şehir endeksi ile yapılan çalışmalara bakıldığında genel itibari ile kısıtlı bir literatüre rastlanmıştır. Yapılan çalışmaların birçoğunda ise tüm şehir endeksleri üzerinde durularak tek şehir endeksi üzerinde yapılan bir çalışma bulunamamıştır. Bu doğrultuda bu çalışmanın sadece İstanbul şehir endeksi üzerinde bir uygulama olası itibari ile özgün bir yapıda olacağı düşünülmektedir. Diğer bir yandan literatür çalışmaları özetlenirken zaten çok az olan çalışmalar kronolojik sıralama göz önünde bulundurularak sunulmuştur.

Aggarwal (1981), çalışmasında, 1974-1978 yılları arasındaki döviz kuru ile hisse senedi fiyatları arasındaki ilişkiyi ele almış ve basit regresyon analizi yöntemini kullanmıştır. Çalışmanın sonucunda, döviz kuru ile hisse senedi getirileri arasında pozitif yönlü bir ilişkinin olduğu tespit edilmiştir.

He ve Ng (1998), çalışmasında, 1979-1993 yıllarını kapsayan ve Japonya'da faaliyet gösteren çok uluslu 171 farklı şirketin hisse senedi fiyatları ile aylık döviz kuru verileri arasındaki ilişkiyi Granger (1969) Nedensellik Testi kullanarak analiz etmişlerdir. Analizden 


\section{Sezgin, $S$.}

elde edilen sonuçta, şirketlerin $1 / 4$ ' üne ait hisse senedi getirileri ile döviz kurları arasında pozitif yönlü ve anlamlı bir ilişkinin olduğu tespit edilmiştir.

Davaslıgil Atmaca (2018), BİST şehir endeksi, ham petrol, Türk Lirası ve Avro döviz kuru getiri serisi verileri arasında istatistiksel olarak anlamlı bir ilişkinin varlığını sorgulandığı çalışmada kalın kuyruk DCC-GARCH modeli kullanılmıştır. 5 Ocak 2009 ile 31 Aralık 2015 dönemi arasında günlük veriler kullanılarak yapılan çalışmanın sonucunda değişkenler arasında anlamlı sonuçlar elde edilmiştir. Ham petrol ve şehir endeksi piyasalarında oynaklık kalıcı özelliklere sahiptir. Antalya şehir endeksi dışındaki tüm endeksler ham petrol serisi ile pozitif korelasyonlu olduğu bulgusu elde edilmiştir.

Kula ve Baykut (2018), GARCH tipi modeller kullanılarak BİST100 de işlem gören 12 tane şehir endeksinin volatilite ve rejim yapılarını test etmeyi amaçlamışlardır. Ocak 2009 ile Temmuz 2017 dönemleri arasında verilerin kullanıldığı çalışmada Adana, Antalya, Balıkesir, Bursa, Denizli, İzmir, Kayseri, Kocaeli, Konya, Tekirdağ ve İstanbul şehir endeksleri örneklem olarak alınmıştır. Analiz sonuçlarına bakıldığında volatilite ısrarcılığı bakımından diğer endekslere nazaran en volatil endeksin Kocaeli Endeksi olduğu görülürken en stabil endeksin Kayseri endeksine ait olduğu gözlemlenmiştir. Çalışmada 12 şehir endeksi arasında yüksel ve düşük olarak 2 tür rejim saptanmış olup endekslerin e yüksek rejimde daha fazla kalmakta ve düşük rejimden yüksek rejime geçme yönünde eğilimi içinde olduğu görülmüştür. En uzun yüksek rejimde kalan endeks 62.06 gün kalarak XSBUR, en kısa yüksek rejimde kalan endeks 9.41 gün kalarak XSADA endeksidir. Düşük rejim sürecine göre incelendiğinde ise, düşük rejimde en yüksek kalan endeks 7.18 günlük değeriyle XSİZM, en düşük rejimde en kısa süre kalan ve düşüş trendinden en hızlı çıkan endeks ise XSKAY'dir.

Bayrakdaroğlu ve Tepeli (2018), BİST100 Şehir endeksinde işlem gören Adana, Antalya, Balıkesir, Bursa, Denizli, İzmir, Kayseri, Kocaeli, Konya, Tekirdağ ve İstanbul şehir endeksleri endekslerine ait 3.12.2012-06.12.2017 dönemleri boyunca beta ve eğim beta değerleri ile risksiz faiz oranı kullanılarak endeksler arasında risk getiri durumu arasında denge olup olmadığını test etmeyi amaçlamıştır. Çalışmanın sonucunda ortalama getiriler incelendiğinde en fazla getiri sağlayan endeks XSKAY, en az getiri sağlayan endeks XSKON endeksidir. Endeksler bir bütün olarak incelendiğinde ise şehir endekslerinin çoğunluğunun getirisi BIST 100 endeksinin getirisinden daha fazladır. Eğim beta değerlerine göre de tüm şehir endeksleri pazarın portföyüyle paralel ilerlediği ve pazara en fazla tepki veren endeksin XSBAL, en az tepki veren endeksin ise XSTKR endeksi olduğu sonucuna ulaşılmıştır. 
Kayral (2020), çalışmasında BİST İstanbul, BİST Ankara ve BİST İzmir Şehir Endeksleri ile dolar ve Euro kurları arasında 01.07.2009 - 01.07.2019 dönemlerini boyunca gerçekleşen günlük fiyat değişimlerini incelemişlerdir. Değişkenler arasında kısa ve uzun dönemli ilişkinin varlığının sınandığı çalışmada ARDL sınır testi kullanılmıştır. Çalışmanın sonunda elde bulgulara bakıldığında tüm şehir endeksleri ile döviz kurları arasında uzun dönemli bir eşbütünleşme olduğu görülürken, kısa dönemde sadece İzmir şehir endeksi ile Euro arasında pozitif yönlü bir ilişkinin olduğuna dair bulgular elde edilmiştir.

\section{METODOLOJÍ}

\section{1. Çalışmanın Amacı, Yöntemi ve Veri Seti}

Yapılan çalışmadaki amaç, döviz kuru ile BİST Şehir Endeksleri içinde işlem gören İstanbul şehir endeksi arasında getiri ve volatilite yayılımının varlığını tespit etmektir.

Bu kapsamda döviz kuru ile BİST İstanbul Şehir Endeksi’nin arasındaki getiri ve volatilite yayılımı 02.01.2014-26.02.2020 tarihleri arasındaki günlük kapanış verileri kullanılarak doğrusal olmayan zaman serisi modellerinden biri olan çok değişkenli VAREGARCH modeli ile ölçülmüştür. Ayrıca değişkenler arasında getiri ve volatilite ilişkisinin test edildiği VAR-EGARCH Modeli analizi RATS (Regression Analysis of Time Series) programı kullanılarak gerçekleştirilmiştir.

\subsection{Durağanlık Analizi ve Birim Kök Testleri}

Çalışma bir zaman serisi olduğu için ilk olarak zaman serilerinden bahsetmek istersek;

Bir değişkenin zaman içerisinde göstermiş olduğu mevcut hareketleri gözlemleyen serilere zaman serisi adı verilmektedir. Formül aşağıdaki gibidir (Bozkurt, 2007: 7-8).

$Y_{i}=\mathrm{T}+\mathrm{C}+\mathrm{S}+\mathrm{I}$ T: Trend, C: Konjonktürel Hareketler, S: Mevsimsellik, I: Stokastik Kısım'ı ifade etmektedir. Tahmini yapılan modelden anlamlı ve güvenilir bir sonuç elde etmek için serinin durağan olması gerekmektedir (Gürsoy ve Eroğlu, 2016: 22).

Eğer seriler durağan değilse modelin en doğru sonucu vermesi açısından serinin durağanlaştırılması gerekmektedir. Bunun için de uygulanan bazı birim kök testleri vardır. Bunlardan en bilinen ve kullanılan testler olan Artırılmış Dickey Fuller (ADF) ve PhillipsPerron (PP) birim kök testleridir (Akdi, 2010: 2-3). 


\section{Sezgin, $S$.}

Fakat bu iki yöntemde de seride meydana gelen yapısal kırılmalar dikkate alınmamaktadır. Bu durumdan dolayı serinin durağanlığını test etmek için yapısal kırılmalarını dikkate alan Zivot-Andrews (ZA) birim kök testi uygulanmıştır.

\subsection{Araştırmada Kullanılan Ekonometrik Model}

$\mathrm{Bu}$ çalışmada kullanılan pay piyasaları arasında aranan istatistiksel ilişki koşullu değişen varyans modelleri kullanılarak gerçekleştirilmiştir. Koşullu değişken modelleri, finansal varlıklardaki oynaklığın tahmin edilmesi ve modellenmesinde en sik kullanılan modellerdir (Çağlayan ve Dayığlu, 2009: 2).

Nelson (1991)'un geliştirdiği tek değişkenli EGARCH modelinin çok değişkenli EGARCH modeline genişletilmesi Koutmos ve Booth (1995) tarafından, bu modelin de çok değişkenli VAR-EGARCH modeli olarak geliştirilmesi Koutmos (1996) tarafından yapılmıştır. Koutmos (1996), bu model sayesinde piyasalar arası etkileşimin ve meydana gelen şokların piyasaların volatilitesi üzerinde oluşturduğu asimetrik etkinin incelenebileceğini belirtmiştir. Çok değişkenli VAR-EGARCH modelini aşağıdaki denklemlerde tanımlamıştır (Demirgil ve Gök, 2014: 327).

$$
\begin{aligned}
& R_{i, t}=\beta_{i, 0}+\sum_{j=1}^{n} \beta_{i, j} R_{j, t-1}+\varepsilon_{i, t} \\
& \sigma_{i, t}^{2}=\exp \left[\alpha_{i, 0}+\sum_{j=1}^{n} \alpha_{i, j} f_{j}\left(z_{j, t-1}\right)+\gamma_{i} \ln \left(\sigma_{i, t-1}^{2}\right)\right] \\
& f_{j}\left(z_{j, t-1}\right)=\left(\left|z_{j, t-1}\right|-E\left(\left|z_{j, t-1}\right|\right)+\delta_{j} z_{j, t-1}\right) \quad j=1,2, \ldots, n \\
& \sigma_{i, j, t}=\rho_{i, j} \sigma_{i, t} \sigma_{j, t} i, j=1,2,3,4 \text { ve } i \neq j
\end{aligned}
$$

1 numaralı denklemde piyasalara ait getiri serileri VAR modeli dahilinde sunulmaktadır. Her bir piyasanın koşullu ortalaması, kendi piyasası ile diğer piyasaların gecikmeli getirileri yansıtacak şekilde çapraz fonksiyon olarak çalışmaktadır. $\beta i, j, i \neq j$ ise getiriler arasındaki gerçekleşen öncül-ardıl ilişkisini ifade etmektedir (Gürsoy ve Gövdere, 2020: 492). 2. denklemde her piyasanın getirileri için koşullu varyans denklemi yer almaktadır. Koşullu varyans piyasaların kendi geçmiş şokları ile çapraz piyasa standartlaştırılmış şoklarının üssel fonksiyonu olup, denklem 3.'de ise geçmiş standartlaştırılmış şokların asimetrik fonksiyonu $f($.) yer almaktadır ki $z j, t-1<0$ için $f($. )'nun eğimi $(-1+\delta j$ )'ye eşitken, $z j, t-1>0$ için eğim $(1+\delta j)$ 'ye eşittir, dolayısıyla denklem 3. piyasaların kendi gecikmeli şokları ve çapraz piyasa şoklarının piyasaların koşullu varyansları üzerine asimetrik olarak etki etmesine izin verir (Koutmos, 1996). 
$\mathrm{Bu}$ modelde $\alpha i j$ ise $i \neq j$ olmak üzere değişkenlerin arasında gerçekleşen volatilite etkileşimini yansıtır ki bu katsayının anlamlı olması $j$ piyasası şoklarının $i$ piyasası volatilitesi üzerine yayılım gösterdiğini ifade etmektedir. Bununla birlikte $i=j$ ise $i$ piyasası volatilitesinin kendi gecikmeli şoklarına bağımlı olduğunu gösterir. $\beta i, j$ ise $i \neq j$ olmak üzere piyasalara ait getiri değerleri arasında gerçekleşen ilişkiyi göstermektedir. Burada eğer katsayı anlamlı ise $j$ değişkenine ait gecikmeli getirileri değerlerinin $i$ piyasasına ait getirileri etkilediğini kanıtlar, bunun yanında $i=j$ eşitliği durumunda $i$ piyasasının getirisinin kendi gecikmeli getiri serisine ne kadar bağımlı olduğunun kanıtlayan bir göstergedir. Diğer bir yandan $\delta j$ terimi $i$ piyasasının asimetrik etkileşimini ifade etmektedir. Eğer denklemde katsayı anlamlı ve negatif ise bunun anlamı negatif şokların pozitif şoklardan daha baskın olduğunun kanıtı niteliğindedir (Demirgil ve Gök, 2014: 327-328).

\subsection{Veri Seti}

Çalışmada günlük döviz kurları ile BİST Şehir Endeksleri arasında bulunan İstanbul şehir endeksi arasındaki getiri ve volatilite yayılımı incelenmiştir. Araştırmada 02.01.201426.02.2020 tarihleri arasındaki günlük döviz kuru verilerinden faydalanılmıştır. Söz konusu veri setine (https://www.investing.com) adresinden ulaşılmıştır.

\section{BULGULAR}

Fiyat serileri ile yapılan analiz sonucunda serinin durağan olmadığg şekil 1.`deki grafiklerden anlaş1lırken Tablo 1.'deki birim kök sonuçlarından elde edilen bulgularla doğrulanmıştır.

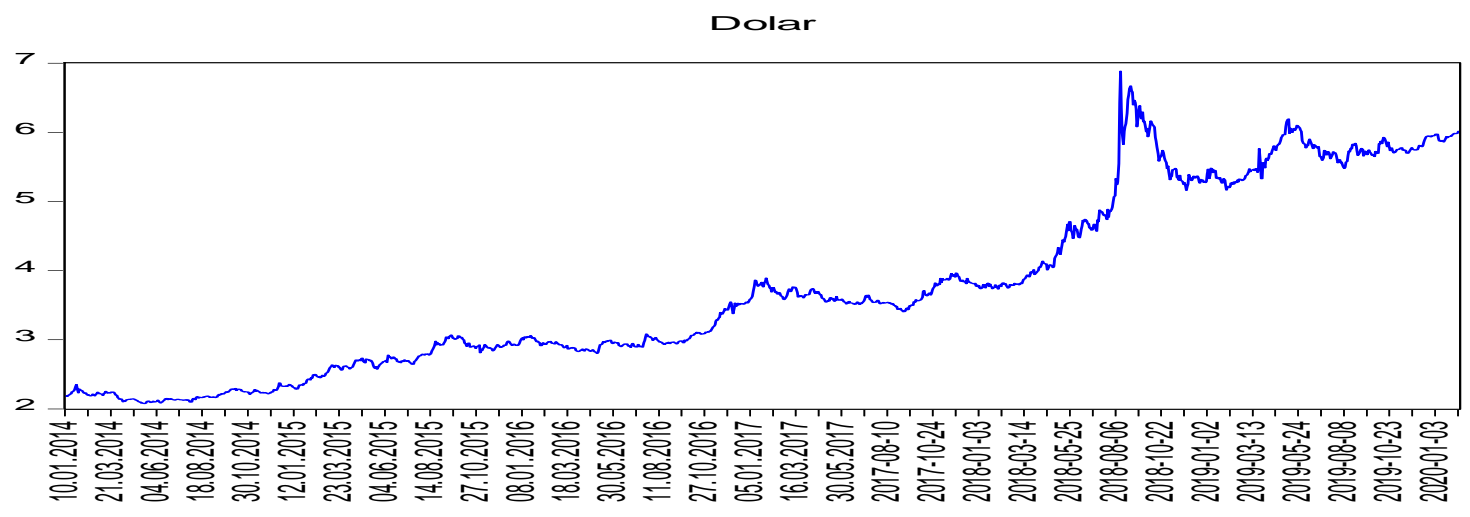


Euro

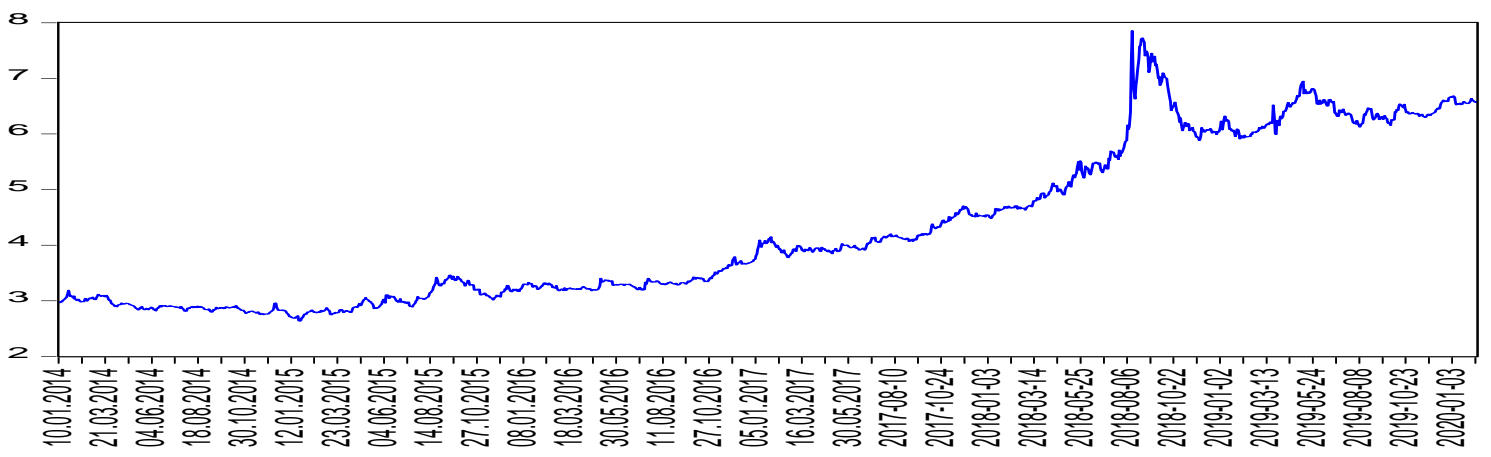

Ist

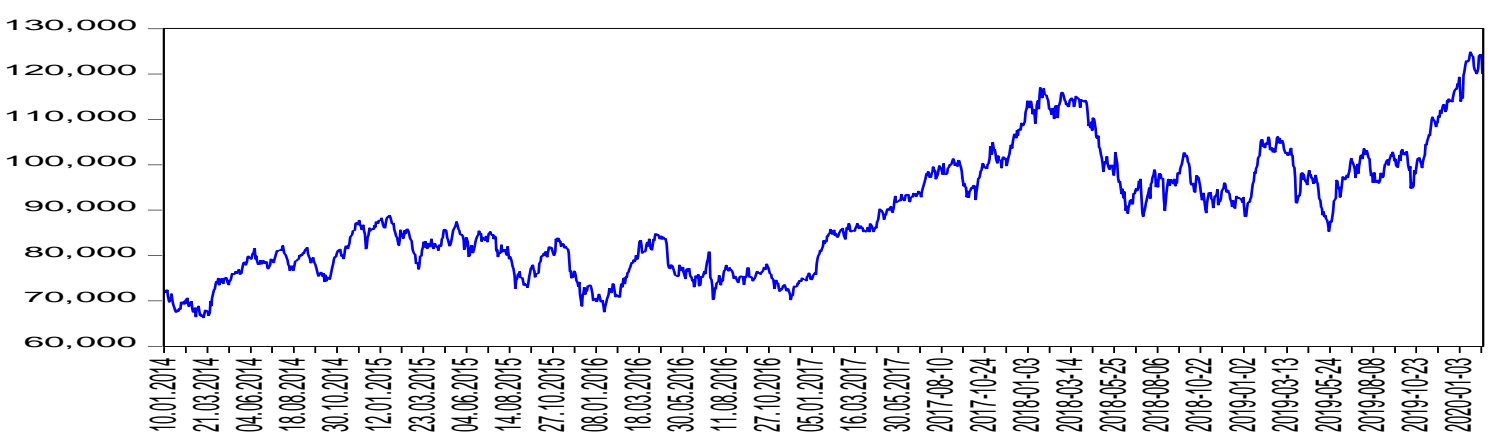

Şekil 1. Değişkenlere ait fiyat seri grafikleri

Serinin durağan olmadığının tespitinin ardından seriyi durağanlaştırmak için uygulanan Zivot-Andrews birim kök testi sonuçları Tablo 1'de verilmiştir.

Tablo 1. Zivot-Andrews birim kök testi sonuçları

\begin{tabular}{|c|c|c|c|c|c|c|}
\hline \multicolumn{7}{|c|}{ Zivot-Andrews (Model C) } \\
\hline \multicolumn{7}{|l|}{ Türkiye } \\
\hline \multirow[b]{2}{*}{ Değişken } & \multirow{2}{*}{\begin{tabular}{|l|} 
Düzey \\
Test \\
İstatistiği
\end{tabular}} & \multirow{2}{*}{$\begin{array}{l}\text { Düzeyin } \\
\text { Kırılma } \\
\text { Tarihi }\end{array}$} & \multirow{2}{*}{$\begin{array}{l}\text { Kritik } \\
\text { Değer }\end{array}$} & \multirow{2}{*}{$\begin{array}{l}\text { 1. Fark } \\
\text { Test } \\
\text { İstatistiği }\end{array}$} & \multirow{2}{*}{$\begin{array}{l}\text { 1.Farkın } \\
\text { Kırılma } \\
\text { Tarihi }\end{array}$} & \multirow{2}{*}{$\begin{array}{l}\text { Kritik } \\
\text { Değer }\end{array}$} \\
\hline & & & & & & \\
\hline Dolar & $-5.37 *$ & 09.07 .2018 & $-5.08 *$ & & & $-5.08 *$ \\
\hline Euro & $-4.50 *$ & 02.05 .2018 & $-5.08 *$ & $-9.97 *$ & 07.09 .2018 & $-5.08 *$ \\
\hline Ist & $-3.35^{*}$ & 05.01 .2017 & $-5.08^{*}$ & $-38.24 *$ & & $-5.08 *$ \\
\hline
\end{tabular}

ZA birim kök testinden elde edilen sonuçlarına göre, Dolar değişkenin I(0) halinde yani düzeyde durağan oldukları görülürken Euro ve İstanbul şehir endeksi değişkeninin ise I(1) halinde yani birinci farkında durağan hale geldiği görülmüştür. Ayrıca söz konusu kırılma tarihlerinde olağan dışı bir durum olmayıp siyasi ve ekonomik politikalardaki hareketlilikler kırılmalara neden olmuştur. 
Çalışmada kullanılan koşullu değişen varyans modellerinden biri olan çok değişkenli VAR-EGARCH modeli için en uygun gecikme değeri araştırılmış ve en uygun gecikme değeri (SC) 3 bulunmuştur. Değişkenlere ait gecikme değeri Tablo 2'de gösterilmiştir.

Tablo 2. Değişkenlere ait gecikme değerleri tablosu

\begin{tabular}{ccccccc}
\hline \hline Lag & LogL & LR & FPE & AIC & SC & HQ \\
\hline \hline 0 & -16865.00 & NA & 4774126. & 23.89235 & 23.90351 & 23.89652 \\
1 & -6654.268 & 20363.62 & 2.531151 & 9.442305 & 9.486946 & 9.458986 \\
2 & -6595.454 & 117.0450 & 2.358713 & 9.371747 & 9.449869 & 9.400938 \\
3 & -6521.467 & 146.9249 & 2.151291 & 9.279698 & $9.391301^{*}$ & 9.321400 \\
4 & -6492.612 & 57.17963 & 2.091633 & 9.251575 & 9.396658 & $9.305787^{*}$ \\
5 & -6478.971 & 26.97307 & 2.077930 & 9.245001 & 9.423565 & 9.311724 \\
6 & -6473.092 & 11.59832 & 2.087143 & 9.249422 & 9.461467 & 9.328656 \\
7 & -6461.838 & 22.15747 & 2.080495 & 9.246230 & 9.491755 & 9.337974 \\
8 & -6451.846 & 19.63084 & $2.077581^{*}$ & $9.244824^{*}$ & 9.523831 & 9.349079 \\
9 & -6443.729 & 15.91267 & 2.080189 & 9.246074 & 9.558562 & 9.362839 \\
10 & -6439.078 & 9.095899 & 2.093057 & 9.252236 & 9.598204 & 9.381511 \\
11 & -6433.154 & 11.56412 & 2.102209 & 9.256592 & 9.636041 & 9.398378 \\
12 & -6418.307 & $28.91559^{*}$ & 2.084887 & 9.248310 & 9.661240 & 9.402607
\end{tabular}

Gecikme uzunluğunun tespitinin ardından çok değişkenli VAR(3) EGARCH tahmin sonuçları Tablo 3 'te sunulmuştur.

Tablo 3. Var(3) Egarch modeli analiz sonuçları (1)

\begin{tabular}{|c|c|c|c|c|c|}
\hline \multicolumn{3}{|c|}{$\mathrm{R}_{\mathrm{i}, \mathrm{t}}=\beta_{\mathrm{i}, 0}+\sum_{\mathrm{j}=1} \beta_{\mathrm{i}, \mathrm{j}} \mathrm{R}_{\mathrm{j}, \mathrm{t}-1}+\varepsilon_{\mathrm{i}, \mathrm{t}}$} & \multicolumn{3}{|c|}{ KOŞULLU ORTALAMA DENKLEMİ } \\
\hline \multicolumn{2}{|c|}{ DOLAR } & \multicolumn{2}{|r|}{ EURO } & \multicolumn{2}{|r|}{ İST } \\
\hline $\begin{array}{l}\text { Ortalama } \\
\text { Denklemi }\end{array}$ & $\begin{array}{c}\text { Katsayı } \\
{[\mathrm{T}] \text { İstatistiği }} \\
\end{array}$ & $\begin{array}{l}\text { Ortalama } \\
\text { Denklemi }\end{array}$ & $\begin{array}{c}\text { Katsayı } \\
\text { [T] İstatistiği } \\
\end{array}$ & $\begin{array}{l}\text { Ortalama } \\
\text { Denklemi }\end{array}$ & $\begin{array}{c}\text { Katsayı } \\
\text { [T] İstatistiği }\end{array}$ \\
\hline $\boldsymbol{R}_{\text {sabit }}$ & $\begin{array}{l}0.0486542 \\
{[2.95148]^{*}}\end{array}$ & $\boldsymbol{R}_{\text {sabit }}$ & $\begin{array}{c}-0.0525649 \\
{[-0.764258]^{*}}\end{array}$ & $\boldsymbol{R}_{\text {sabit }}$ & $\begin{array}{l}0.0425219 * * \\
{[1.52424]}\end{array}$ \\
\hline$R_{D O L, D O L(-1)}$ & $\begin{array}{c}-0.0745620 \\
{[3.10951]^{*}}\end{array}$ & $R_{E U R, E U R(-1)}$ & $\begin{array}{c}0.0608459 \\
{[1.627150]^{*}}\end{array}$ & $R_{\text {IST, IST (-1) }}$ & $\begin{array}{l}-0.0785425 * * \\
{[-0.573638]}\end{array}$ \\
\hline$R_{D O L, D O L(-2)}$ & $\begin{array}{c}0.0228541 \\
{[1.36987]^{* * *}}\end{array}$ & $R_{E U R, E U R(-2)}$ & $\begin{array}{r}0.0438357 \\
{[1.76234]} \\
\end{array}$ & $R$ iST, iST (-2) & $\begin{array}{l}0.0255861 \\
{[0.21849]} \\
\end{array}$ \\
\hline$R_{D O L, D O L(-3)}$ & $\begin{array}{c}0.0241368 \\
{[1.14281]}\end{array}$ & $R_{E U R, E U R(-3)}$ & $\begin{array}{c}0.0538875 \\
{[1.96262]^{* * *}}\end{array}$ & $R$ IST, iST (-3) & $\begin{array}{l}0.0155845 \\
{[0.21159]}\end{array}$ \\
\hline$R_{D O L, E U R(-1)}$ & $\begin{array}{c}0.074526 \\
{[-0.89745]^{* *}}\end{array}$ & $R_{E U R, D O L(-1)}$ & $\begin{array}{c}-0.055691 \\
{[-0.71525]^{*}}\end{array}$ & $R_{i S T, D O L(-1)}$ & $\begin{array}{l}-0.0541367 \\
{[1.55524]^{* *}}\end{array}$ \\
\hline$R_{D O L, E U R(-2)}$ & $\begin{array}{c}-0.0631485 \\
{[-0.812424]^{* *}}\end{array}$ & $R_{E U R, D O L(-2)}$ & $\begin{array}{c}-0.0486231 * * \\
{[-0.72714]} \\
\end{array}$ & $R$ iST, DOL(-2) & $\begin{array}{l}-0.0586529 \\
{[1.32474]^{* * *}}\end{array}$ \\
\hline$R_{D O L, E U R(-3)}$ & $\begin{array}{c}-0.0374695 \\
{[-0.72862]^{* * *}}\end{array}$ & $R_{E U R, D O L(-3)}$ & $\begin{array}{c}-0.0284239 * * \\
{[-0.82751]} \\
\end{array}$ & $R$ iST, DOL(-3) & $\begin{array}{l}-0.0446515 \\
{[1.10494]}\end{array}$ \\
\hline$R_{D O L, ~ i S T(-1)}$ & $\begin{array}{c}-0.0156561 \\
{[-0.91386]} \\
\end{array}$ & $R_{E U R, ~ i S T(-1)}$ & $\begin{array}{c}0.0240134 * * * \\
{[0.78954]}\end{array}$ & $R_{i S T, E U R(-I)}$ & $\begin{array}{l}-0.0984294 \\
{[0.85485]^{* *}}\end{array}$ \\
\hline$R_{D O L, \text { IST(-2) }}$ & $\begin{array}{c}-0.01225365 \\
{[0.52417]} \\
\end{array}$ & $R_{E U R, ~ I S T(-2)}$ & $\begin{array}{c}-0.0001411 \\
{[0.14329]} \\
\end{array}$ & $R$ IST, EUR(-2) & $\begin{array}{l}0.0021810 \\
{[0.49857]} \\
\end{array}$ \\
\hline$R_{D O L, ~ I S T(-3)}$ & $\begin{array}{c}-0.0265545 * * * \\
{[0.82428]} \\
\end{array}$ & $R_{E U R, ~ I S T(-3)}$ & $\begin{array}{c}0.0031425 \\
{[0.15210]} \\
\end{array}$ & $R$ iST, EUR(-3) & $\begin{array}{l}-0.0021810 \\
{[0.49857]}\end{array}$ \\
\hline \multicolumn{6}{|c|}{ Anlamlılık düzeyi için : *\%1. **\%5. ***\%10 işaretleri kullanılmıştır. } \\
\hline
\end{tabular}


Tablo 4. Var (3) Egarch modeli analiz sonuçları (1) devamı

\begin{tabular}{|c|c|c|c|c|c|}
\hline \multicolumn{4}{|c|}{$\sigma_{i, t}^{2}=\exp \left[\alpha_{i, 0}+\sum_{j=1}^{n} \alpha_{i, j} f_{j}\left(z_{j, t-1}\right)+\gamma_{i} \ln \left(\sigma_{i, t-1}^{2}\right)\right]$} & \multicolumn{2}{|c|}{ KOŞULLU VARYANS DENKLEMİ } \\
\hline \multicolumn{2}{|c|}{ DOLAR } & \multicolumn{2}{|r|}{ EURO } & \multicolumn{2}{|r|}{ IST } \\
\hline $\begin{array}{c}\text { Varyans } \\
\text { Denklemi }\end{array}$ & $\begin{array}{c}\text { Katsayı } \\
\text { [T] İstatistiği }\end{array}$ & $\begin{array}{c}\text { Varyans } \\
\text { Denklemi }\end{array}$ & $\begin{array}{c}\text { Katsayı } \\
\text { [T] İstatistiği }\end{array}$ & $\begin{array}{c}\text { Varyans } \\
\text { Denklemi }\end{array}$ & $\begin{array}{c}\text { Katsayı } \\
\text { T] İstatistiği }\end{array}$ \\
\hline Asabit & $\begin{array}{l}-0.0314147 \\
{[-1.94582]^{*}}\end{array}$ & Asabit & $\begin{array}{l}-0.0874321 \\
{[-5.86241]^{*}}\end{array}$ & Asabit & $\begin{array}{l}-0.1568364 \\
{[-2.14656]^{*}}\end{array}$ \\
\hline $\begin{array}{c}A R C H \\
A_{D O L, D O L} \\
\end{array}$ & $\begin{array}{c}0.4529824 \\
{[6.46452]^{* *}}\end{array}$ & $\begin{array}{c}A R C H \\
A_{E U R, E U R} \\
\end{array}$ & $\begin{array}{l}0.0543842 \\
{[7.15393]} \\
\end{array}$ & $\begin{array}{l}\text { ARCH } \\
A_{\text {IST, iST }}\end{array}$ & $\begin{array}{l}0.0358147 \\
{[5.48135]^{* * *}}\end{array}$ \\
\hline$A_{D O L, E U R}$ & $\begin{array}{l}0.0989645 \\
{[6.40988]^{*}}\end{array}$ & $A_{E U R, D O L}$ & $\begin{array}{l}-0.0396352 \\
{[4.23589]^{*}}\end{array}$ & $A_{\text {IST, DOL }}$ & $\begin{array}{l}-0.052658 * * \\
{[5.05147]}\end{array}$ \\
\hline$A_{D O L, \text { iST }}$ & $\begin{array}{l}-0.035125 \\
{[-1.07126]}\end{array}$ & 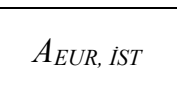 & $\begin{array}{l}0.0104774 \\
{[1.10317]}\end{array}$ & AIST, EUR & $\begin{array}{l}0.0572662 \\
{[3.24982]^{*}}\end{array}$ \\
\hline$\delta_{1}$ & $\begin{array}{c}-0.4914238 \\
{[-2.75240]^{*}}\end{array}$ & $\delta_{2}$ & $\begin{array}{l}-0.4332154 \\
{[-3.54289]^{*}}\end{array}$ & $\delta_{3}$ & $\begin{array}{l}0.8824671 \\
{[3.15258]^{*}}\end{array}$ \\
\hline GARCH $\gamma_{1}$ & $\begin{array}{c}0.7912246 \\
{[192.27114]^{*}}\end{array}$ & $\mathrm{GARCH} \gamma_{2}$ & $\begin{array}{c}0.7225419 \\
{[129.28750]^{*}}\end{array}$ & $\mathrm{GARCH} \gamma_{3}$ & $\begin{array}{l}0.9185387 \\
{[399.01728]}\end{array}$ \\
\hline LB-Q & $\begin{array}{c}6.159 \\
{[0.314528]}\end{array}$ & LB-Q & $\begin{array}{c}14.258 \\
{[0.298757]}\end{array}$ & LB-Q & $\begin{array}{l}37.218 \\
{[0.524038]}\end{array}$ \\
\hline ARCH-LM & $\begin{array}{c}5.067477 \\
{[0.28512829]}\end{array}$ & ARCH-LM & $\begin{array}{c}5.005604 \\
{[0.70820017]}\end{array}$ & ARCH-LM & $\begin{array}{l}7.376200 \\
{[0.19147114]}\end{array}$ \\
\hline \multirow{3}{*}{\multicolumn{3}{|c|}{$\begin{array}{c}\text { Anlamlılık düzeyi için : *\%1. **\%5. ***\%10 } \\
\text { işaretleri kullanılmıştır }\end{array}$}} & \multicolumn{3}{|c|}{ Tablodaki kısaltmalar } \\
\hline & & & r: Getiri & \begin{tabular}{c|}
$\delta_{1}:$ Kaldıraç \\
etkisi
\end{tabular} & $\begin{array}{l}\text { LB-Q: Otokorelasyon } \\
\text { Testi }\end{array}$ \\
\hline & & & A:Volatilite & $\begin{array}{c}\gamma 1: \text { Volatilite } \\
\text { Kalıc1lığ } 1 \\
\end{array}$ & $\begin{array}{l}\text { ARCH-LM: Değişen } \\
\text { Varyans Testi }\end{array}$ \\
\hline
\end{tabular}

Dolar için kurulmuş getiri hakkında bilgi veren ortalama denklemi sonuçlarına göre dolar kendisinin bir ve iki gün önceki getirilerinden, Euro'nun her üç gündeki getirilerinden ve İstanbul şehir endeksinin yalnızca 3 gün önceki getirilerinden etkilenmiştir. Varyans denklemi sonuçlarına göre ise İstanbul şehir endeksi hariç diğer değişkenlerden dolara doğru anlamlı bir volatilite yayılımı vardır. Kaldıraç parametresine göre piyasada negatif şoklar daha baskındır. 0.79 kalıcılık oranı incelendiğinde dolar üzerinde meydana gelen bir dalgalanma kısa sürede etkisini yitirmektedir. Yapılan tanı testleri sonucunda modelde otokorelasyon ve değişen varyans sorunu olmadığ tespit edilmiştir.

Euro için kurulan modelin ortalama denklemi sonuçlarına göre kendisinin geçmiş getirileri dahil dolar ve İstanbul şehir endeksinin geçmiş getirilerinden etkilenmektedir. En güçlü getiri yayılımı kendisinin üç gün önceki ve İstanbul şehir endeksinin bir gün önceki getirileri üzerinden olmuştur. Koşullu varyans denklemi sonuçlarına göre yalnızca dolar ile Euro arasında çift taraflı ve anlamlı bir volatilite yayılımı vardır. Kaldıraç etkisi sonucuna göre değişken üzerinde negatif şoklar pozitif şoklara göre daha anlamlı bir etkiye sahiptir. $\gamma 2$ parametresine göre Euro üzerinde oluşan dalgalanma uzun süre etkili olmamaktadır. Koşullu 
değişen varyans modellerinin artıkları için yapılan tanı testlerinin sonucuna göre modelde otokorelasyon ve değişen varyans sorununa rastlanmamıştır.

İstanbul için oluşturulan öncül-ardıl ilişkiler bağlamında kanıt sunan ortalama denklemi sonucuna göre İstanbul şehir endeksi kendisi ve Euro'nun bir gün önceki, doların bir ve iki gün önceki getirilerinden etkilenmektedir. Koşullu varyans denkleminden elde edilen bulgular neticesinde İstanbul şehir endeksi üzerinde kendisinin ve Euro'nun anlamlı bir volatilite yayılımı vardır. En güçlü yayılım kendi geçmiş şokları üzerinden olmuştur. Asimetri (kaldıraç) parametresine göre piyasada pozitif şoklar negatif şoklara göre daha baskındır. 0,91 kalıcılık oranına göre piyasaya giren bir şok piyasa üzerinde uzun süren bir etkiye sahiptir. Tanı testlerinden elde edilen sonuçlara göre kurulan modelde otokorelasyon ve değişen varyans sorunu yoktur.

\section{SONUÇ VE ÖNERILER}

Döviz kurlarındaki değişimler, borsada yer alan endekslerin durumları yatırımcıların sık1 takibinde olduğu para ve sermaye piyasası göstergeleri arasında yer alır. Bu bağlamda söz konusu göstergelerin kısa ve uzun dönemdeki değişimleri finans alanında yapılan çalışmaların alt yapısını oluşturmaktadır. Ayrıca şehir ve bölge bazlı yatırım yapmak isteyenler için ise bu alanda yapılan çalışmalar büyük önem arz etmektedir. Bu bağlamda bu çalışmada yapılan analiz sonucundan elde edilen ampirik bulguların İstanbul şehir endeksinde 27.03.2020 tarihi itibari ile işlem gören 101 firmanın döviz duyarlılığını ortaya koyması açısından gerek şirket paydaşları gerekse şirket hissedarları açısından yol gösterici olacağı düşünülmektedir.

Bu çalışma kapsamında öncelikli olarak günlük veriler şeklinde elde edilen ham veriler üzerinde birim kök testi yapılarak durağanlık analizi gerçekleştirilmiştir. Zivot-Andrews Birim Kök ile bir kırılma dikkate alınarak yapılan çalışma sonunda verilerin durağanlıkları sağlanarak ayrıca kırılma tarihleri paylaşılmıştır. Veriler üzerinde gerçekleşen kırılma tarihlerinin kısaca açıklandığı analiz kısmından daha sonra en uygun gecikme uzunluğu (SC) 3 gün olduğu görülmüştür ve bu gecikme uzunlukları dikkate alınarak, 2014-2020 yılları arasını kapsayan İstanbul şehir endeksi ile Dolar ve Euro arasındaki getiri ve volatilite yayılımı çok değişkenli VAR-EGARCH modeli çalıştırılmıştır.

Yapılan analiz sonucunda; İstanbul şehir endeksi ile döviz kurları arasında karşılıklı getiri yayılımı olduğu görülmüştür. Volatilite yayılımı açısından incelendiğinde döviz kurlarındaki negatif şoklar pozitif şoklara göre volatiliteyi daha çok etkilediği anlaşılmaktadır. 


\section{Sezgin, $S$.}

Bununla birlikte İstanbul şehir endeksi değişkeni üzerinde pozitif şokların negatif şoklardan daha baskın olduğu görülürken ayrıca endeksin döviz kurlarında gerçekleşen geçmiş şoklarından etkilendiği görülmektedir. Bu durum başta İstanbul şehir endeksinde yer alan ve uluslararası ticaret yapan firmaları, beraberinde o firmaların borsada işlem gören hisse senetlerine yatırım yapmak isteyen yatırımcıları olumsuz yönde etkileyeceği söylenebilmektedir. Bu sonuçlar Davaslıgil Atmaca (2018), Kayral (2020) çalışmaları ile benzer özellikler göstermektedir. Son olarak çalışmanın sonucunda anlaşılmıştır ki, bu alanda yapılacak olan çalışmalar için sadece döviz kurlarının endeksler üzerindeki etkisi yerine, VIX (korku endeksi) gibi Uluslararası risk endeksleri, altın, gümüş gibi emtia borsası araçlarının da dahil olduğu çalışmaları yapılması, endeks üzerindeki değişimleri daha geniş bir perspektiften görme imkânı sağlayacaktır.

\section{REFERENCES / KAYNAKLAR}

Aggarwal, R. (1981). Exchange rates and stock prices: A study of U.S. capital market under floating exchange rates. Akron Business and Economic Review, 12(2), 7-12.

Akdi, Y. (2010). Zaman serileri analizi (birim kökler ve kointegrasyon). Ankara: Gazi Kitabevi.

Bayrakdaroğlu, A. \& Tepeli, Y. (2018). BİST şehir endekslerinin risk-getiri analizi üzerine bir inceleme. Muhasebe ve Finansman Dergisi, (80), 147-160. doi: 10.25095/mufad.465922

Bozkurt, H. (2007). Zaman serileri analizi. Bursa: Ekin Kitap Evi.

Çağlayan, E. \& Dayığlu, T. (2009). Döviz kuru getiri volatilitesinin koşullu değişen varyans modelleri ile öngörüsü. Ístanbul Üniversitesi İktisat Fakültesi Ekonometri ve Ístatistik Dergisi, (9), 1-16.

Davaslıgil Atmaca, V. (2018). BİST şehir endeksleri oynaklığının DCC-GARCH model ile analizi. Yönetim Bilimleri Dergisi, 16(31), 287-308.

Demirgil, H. \& Gök, İ. Y. (2014). Türkiye ve başlıca AB pay piyasaları arasında asimetrik volatilite yayılımı. Yönetim ve Ekonomi Araştırmaları Dergisi, 12(23), 315-340. doi: 10.11611/JMER244

Ergün, B. (2010). IMKB-100 endeksinde oynaklı̆̆ın doğrusal olmayan zaman serileri ile modellenmesi (Yüksek lisans tezi). Dokuz Eylül Üniversitesi, İzmir.

Gürsoy, S. \& Eroğlu, Ö. (2016). Yükselen ekonomilerin pay piyasaları arasında getiri ve volatilite yayılımı: 20062015 yılları arasında yapılmış bir analiz. Mehmet Akif Ersoy Üniversitesi İktisadi ve İdari Bilimler Fakültesi Dergisi, 3(1), 16-33.

Gürsoy, S. \& Gövdere, G. (2020). Uluslararası pay piyasaları arasındaki getiri ve volatilite yayılımı: Gelişmiş ülkeler ve seçilmiş gelişmekte olan ülkeler üzerine bir inceleme. Süleyman Demirel Üniversitesi Vizyoner Dergisi, $11(27), 487-502$.

He, J. (1998). The foreign exchange exposure of Japanese multinational corporation. Journal of Finance, 53, 733753.

Investing.com. Erişim tarihi: 20.02.2020, https://www.investing.com 
Kamuyu Aydınlatma Platformu (KAP). Erişim tarihi: 27.03.2020, https://www.kap.org.tr/tr/Endeksler

Kayral, İ. E. (2020). BİST şehir endeksleri ile döviz kurları arasındaki ilişkinin incelenmesi: Bir ARDL sınır testi uygulamas1. IBAD Sosyal Bilimler Dergisi, (6), 272-284. Doi: 10.21733/ibad.668915

Koutmos, G. (1996). Modeling the Dynamic Interdependence of Major European Stock Markets. Journal of Business Finance \& Accounting, 23(7), 975-988.

Kula, V. \& Baykut, E. (2018). Bist şehir endekslerinin volatilite yapıları ve rejim değişimlerinin analizi. Muhasebe ve Finans Incelemeleri Dergisi, 1(1), 38-59. 